\title{
OCTAVIO PAZ COMO LECTOR CRÍTICO DE LA POESÍA MEXICANA MODERNA
}

Carecemos de estudios dedicados a investigar los modos de conformación del canon poético mexicano. ¿Cómo llega a constituirse ese conjunto de obras privilegiadas que gozan de prestigio jerárquico como textos clásicos de una tradición cultural? ¿Desde dónde se hace el trabajo de construcción y con qué fines? ¿Cómo se regula ese sistema dinámico de lo canónico y lo marginal? No pretendo, desde luego, contestar las preguntas anteriores en estas páginas sino tratar de iluminar algunos aspectos parciales mediante el análisis de un caso especial: la relación de un poeta central con su tradición inmediata. Sabemos que los cánones no son conjuntos eternos de textos sino configuraciones inestables que están sujetas a cambios constantes según las variaciones en el gusto estético o en el entorno ideológico y cultural. Sostengo aquí que en el caso de la poesía mexicana moderna, las distintas reformulaciones del canon han sido realizadas, en primer lugar, por los poetas con el apoyo posterior de los críticos profesionales. Ver a los poetas como los inventores principales del canon lleva necesariamente a una reflexión sobre sus modos de leer y sobre los motivos que pudieran explicar sus preferencias. Aclaro que este deseo de enfocar sólo aspectos de la conformación creadora inicial explica mi desinterés aquí en la institucionalización posterior del canon como dogma prescriptivo.

Hay dos ensayos clásicos de poetas-críticos modernos que nombran y ejemplifican este proceso de reinvención creadora del canon. El primer texto es de T. S. Eliot. En "Tradition and the individual talent", ensayo escrito en 1919 en plena época de eclosión de las vanguardias históricas que vociferaban tanto su rechazo programático al arte del pasado como su culto a la novedad, Eliot propone una teoría impersonal de la creación y 
argumenta que todo acto de escritura es por fuerza un diálogo con los muertos. Una tradición literaria constituye un "orden simultáneo" u "orden ideal" en el cual el presente coexiste con el pasado:

The historical sense involves a perception, not only of the pastness of the past, but of its presence; the historical sense compels a man to write not merely with his own generation in his bones, but with a feeling that the whole of the literature of Europe from Homer and within it the whole of the literature of his own country has a simultaneous existence and composes a simultaneous order ${ }^{1}$.

Para Eliot, cada obra realmente nueva es capaz de provocar un reacomodo de toda la tradición anterior; la siempre relativa novedad de una obra de arte sólo se percibe contra el trasfondo de un pasado vivo en el presente. Los cambios y las rupturas introducidos por el arte del presente implican no la negación sino la reconfiguración del sistema sincrónico de la tradición. Esta reconfiguración es lo que Eliot intentó lograr mediante la técnica del collage intertextual y polifónico que provee la estructura fragmentaria de su poema extenso The waste land (1922), texto que impresionó profundamente al joven Octavio Paz cuando lo leyó en 1930, en la traducción prosificada que Enrique Munguía publicó en la revista Contemporáneos.

En 1951 Borges plasma en su ensayo "Kafka y sus precursores" una idea parecida a la de Eliot: "El hecho es que cada escritor crea a sus precursores. Su labor modifica nuestra concepción del pasado, como ha de modificar el futuro" 2 . Borges incluso alude a Eliot en este momento de su texto: discute (sin nombrarlo) el ensayo mencionado arriba. El título del libro citado por Borges (Points of view, antología de escritos críticos de Eliot publicada en 1941) indica esta pluralidad creadora de perspectivas. Pero Borges no sólo teoriza sino que también pone en práctica la idea de que toda lectura reescribe el texto leído y de que esta relectura de la tradición implica la inversión de la relación entre pasado y presente. Al igual que Eliot, Borges había practicado en una obra de creación esta nueva forma de leer y reescribir a los clásicos. En "Pierre Menard, autor del Quijote" (1939) la idea se enuncia de la siguiente manera: "Menard

${ }^{1}$ En Selected essays, 3 $3^{\text {rd }}$ ed., Faber and Faber, London, 1951, p. 14.

${ }^{2}$ En Obras completas, Emecé, Buenos Aires, 1974, p. 712. 
(acaso sin quererlo) ha enriquecido mediante una técnica nueva el arte detenido y rudimentario de la lectura: la técnica del anacronismo deliberado y de las atribuciones erróneas"3. Apenas es necesario agregar que la teoría desarrollada en libros como The anxiety of influence (1973) por el crítico norteamericano Harold Bloom (que ve en la poesía un fenómeno permanente de misreading, revisionismo y desviación creadora, actividades practicadas por los poetas al leerse unos a otros) parte de una lectura (revisionista) de los textos mencionados de Eliot y Borges (entre otros), figuras que también pueden verse como dos de los precursores de Paz que éste, a su vez, reescribirá.

Pero en lugar de generalizar, prefiero limitar mis comentarios al caso central de Octavio Paz, poeta y crítico que a lo largo de su carrera mostró un sostenido interés, por no decir pasión o incluso obsesión, por la vigencia y transformación del canon poético en México. Sus preocupaciones no se limitaban, desde luego, a la tradición nacional ni al género de la lírica, pero creo que es en sus escritos sobre poesía mexicana donde podemos ver con cierta claridad el despliegue de los mecanismos cuyo análisis puede ayudar a entender el problema que nos ocupa. Entiendo que Paz no ha sido el primero ni será el último en pugnar por la reformulación de un canon poético en México, pero su caso es único por la extensión y la profundidad de sus contribuciones. De hecho, me parece que su labor en este campo sólo tiene parangón en las reordenaciones igualmente hegemónicas que Eliot y Borges realizaron en sus respectivos cánones nacionales.

Podríamos preguntarnos, en primer lugar, ¿dónde lleva a cabo Octavio Paz su revisión y propuesta reformadora del canon? Pensaríamos en sus ensayos sobre otros poetas mexicanos, en sus textos panorámicos y en sus prólogos o epílogos a distintas antologías de poesía mexicana e hispánica. Es cierto, pero creo que habría que agregar que esta lectura del canon se da también, y tal vez en forma privilegiada, en su poesía, en la cual constantemente dialoga con sus antecesores y a veces con algunos contemporáneos. Sin embargo, en estas páginas me limitaré a analizar algunos de sus ensayos sobre varios poetas mexicanos anteriores del siglo xx y a comentar un par de sus textos más panorámicos. También haré referencia (en forma breve y sin pretensiones analíticas exhaustivas) a ciertos poe-

${ }^{3}$ En Obras completas, p. 450. 
mas suyos que parecen tener una relación muy directa con los de los poetas que el autor va leyendo e interpretando en sus ensayos críticos. Ciertamente, hay otro aspecto importante relacionado con el papel de Paz como constructor del canon poético nacional: me refiero a sus contribuciones como antólogo, sobre todo como la presencia dominante en la influyente selección Poesía en movimiento. México, 1915-1966, publicada en 1966. Como he escrito en otro lugar sobre este aspecto, no lo trato aquí ${ }^{4}$. Casi todos los ensayos que comentaré se encuentran recopilados en el cuarto tomo de las Obras completas de Paz, tomo que incluye la mayor parte de sus textos críticos sobre literatura mexicana ${ }^{5}$.

Paz ha sido un intérprete y un artífice de tradiciones. La influencia de sus lecturas ha sido enorme y, sin embargo, nunca se propuso escribir una historia de la poesía mexicana y hay poetas importantes sobre quienes no dejó ensayos autónomos. Al examinar sus textos críticos sobre poesía mexicana es fácil percibir ciertas preferencias y reticencias. Entre estas últimas, por ejemplo, hay que destacar su escaso interés en los poetas románticos y modernistas. Incluso podemos decir que hay períodos enteros que no parecen interesarle: los juicios sobre los poetas mexicanos del siglo XIX son casi tan severos como las opiniones sobre la producción del siglo xvIII. Sus lecturas suelen ser parciales e interesadas, productos de circunstancias definidas, y tal vez para comprenderlas en su totalidad habría que reconstruir en detalle los contextos originales, tarea que no puedo realizar aquí.

En el prólogo, escrito en 1991, al ya citado tomo 4 de sus obras completas, el autor hace una caracterización autocrítica de sus textos sobre poesía mexicana al presentarlos como "ejercicios de entusiasmo" (p. 24). Este aspecto hondamente personal, que no excluye exaltaciones, polémicas y disensiones, sin duda sirve como indicio de la naturaleza funcional o complementaria de estos escritos críticos en relación con la obra propiamente creadora del poeta. No obstante, el carácter fragmentario y no sistemático de su crítica no debe ocultarnos su

${ }^{4}$ Véase "Tres antologías: la formulación del canon", cap. inicial de mi libro Inventores de tradición: ensayos sobre poesía mexicana moderna, El Colegio de México-F.C.E., México, 1998, esp. pp. 51-60.

${ }^{5}$ Generaciones y semblanzas: dominio mexicano, t. 4 de las Obras completas, 2a ed., F.C.E., México, 1994. En adelante todas las referencias dadas entre paréntesis en el texto remiten a esta edición. 
coherencia $^{6}$. Una y otra vez el autor desarrolla y rectifica sus opiniones anteriores sobre los mismos temas, rasgo que fue bien percibido por uno de los pocos críticos que ha estudiado como un conjunto los ensayos de Paz sobre poesía mexicana: "Se trata de un claro proceso de crecimiento y maduración; un constante retorno y enriquecimiento; una prolongación y refinamiento de lo que ya estaba en él desde la primera etapa de su crítica literaria"'? Por otra parte, este movimiento en forma de espiral se corresponde, por lo menos parcialmente, con la lógica interna de su modelo de explicación, como se verá más adelante.

Si tuviera que adelantar lo que constituye para mí el rasgo más distintivo y original de estas lecturas, subrayaría, sobre todo, su carácter estratégico: hay siempre un intento por definirse a sí mismo frente a sus antecesores y sus contemporáneos y forjar un espacio propio no colonizado por sus precursores. En mis comentarios sobre los ensayos críticos de Paz me detendré primero en los textos más panorámicos para analizar después los escritos dedicados a figuras particulares.

Desde muy joven, Octavio Paz se planteó la pregunta acerca de la existencia de una tradición poética específicamente mexicana. ¿Desde cuándo existe? ¿Qué incluye y qué excluye? ¿Cuáles son sus características constitutivas? En algunos de sus tempranos ensayos Paz discute la teoría codificada por Pedro Henríquez Ureña acerca de las supuestas notas distintivas de la sensibilidad mexicana. Recordemos la teoría que expuso el ateneísta dominicano en su conferencia sobre Juan Ruiz de Alarcón, pronunciada el 6 de diciembre de 1913. Henríquez Ureña sostiene que la poesía mexicana se caracteriza por "el sentimiento discreto, el tono velado, el matiz crepuscular" y establece correspondencias con el paisaje y el clima del altiplano:

La discreción, la sobria mesura, el sentimiento melancólico, crepuscular y otoñal, van concordes con este otoño perpetuo de las alturas, bien distinto de la eterna primavera fecunda de los trópi-

${ }^{6}$ Ya en 1968 Emir Rodríguez Monegal señaló la existencia en Paz de "un cuerpo crítico que tiene, a pesar de su aparente dispersión, una enorme coherencia interior" ("Octavio Paz: crítica y poesía", Mundo Nuevo, marzo de 1968, núm. 21, p. 60).

7 Allen W. Phillips, "Octavio Paz: crítico de la poesía mexicana moderna”, Cinco estudios sobre literatura mexicana moderna, SepSetentas, México, 1974, p. 150. 
cos: este otoño de temperaturas discretas que jamás ofenden, de crepúsculos suaves y de noches serenas ${ }^{8}$.

En "Émula de la llama", ensayo cuya primera versión fue escrita en 1942 y publicada a principios de 1943 con el título de "Pura, encendida rosa"9, Paz no rechaza del todo aquel estereotipo sino que trata de ampliarlo: el tono crepuscular no es toda la poesía mexicana, pero sí constituye una línea importante y central de la misma. Le irrita el reduccionismo más que la idea de una esencia de lo mexicano plasmada en la poesía. En aquel momento Paz parece creer en la noción de un alma nacional como fundamento de una tradición poética. Para someter a prueba la teoría de Henríquez Ureña, se propone determinar la hora del día que le corresponde a una selección de poetas mexicanos y dedica un párrafo a cada uno. Conforman la lista Díaz Mirón, Othón, Urbina, González Martínez, López Velarde, Reyes, Pellicer, Gorostiza y Villaurrutia. Los únicos que rompen claramente con el estereotipo melancólico y crepuscular son Díaz Mirón, poeta del "mediodía pleno" (p. 55); Pellicer, "el poeta de la mañana” (p. 58); y Gorostiza, asociado con "la madrugada" ( $i d$.$) -Paz se refiere al$ autor de las Canciones para cantar en las barcas y no al creador del ambiente insomne de Muerte sin fin. En el límite de lo crepuscular está Villaurrutia, "un poeta nocturno" $(i d$.$) . El autor concluye$ que "el crepúsculo no define a todos los poetas mexicanos. Cada uno tiene su hora, su espacio y su luz propia” (p. 59).

Los modelos de este ensayo son claros: tanto Henríquez Ureña como Reyes (en Visión de Anáhuac y otros textos) habían sostenido esta noción, pero la fuente más directa para el joven Paz es una conferencia dictada en el mismo año de 1942 por Xavier Villaurrutia en la Universidad Michoacana. En "Introducción a la poesía mexicana" Villaurrutia establece un claro paralelismo e incluso identidad entre rasgos del supuesto carácter nacional y las notas sobresalientes de la tradición poética mexicana ("su apartamiento, su soledad, su aristocracia, su tono íntimo de confesión, su carácter reflexivo y meditativo, su

8 “Don Juan Ruiz de Alarcón”, Nosotros, marzo de 1914, núm. 9, p. 187. Para un análisis más amplio de la fortuna de esta teoría de las notas distintivas de la poesía mexicana y de su gravitación en el joven Paz, véase mi ensayo "Alarcón y la construcción de la tradición poética mexicana", Inventores de tradición, pp. 90-102.

9 "Pura, encendida rosa”, Hoy, 9 de enero de 1943, núm. 307, pp. 56-57. 
color y su hora"10) y destaca a dos "poetas solares" que son excepciones que confirman la regla: Díaz Mirón y Pellicer. En sus respectivos textos de 1942 Villaurrutia y Paz no rechazan el estereotipo crepuscular sino que señalan su incapacidad de albergar toda la gama de poetas mexicanos modernos.

Unos años después, en la "Introducción a la historia de la poesía mexicana", escrita en 1950 y publicada como prólogo a la Anthologie de la poésie mexicaine que la UNESCO editó en 1952 en París, Paz desarrolla sus ideas con mayor amplitud y deja atrás las tesis "nacionalistas". El texto del prólogo es necesariamente esquemático, pero su importancia reside en el hecho de que Paz esboza aquí, por primera vez, su opinión sobre las grandes líneas de la historia de la poesía mexicana desde el siglo XvI hasta principios del siglo xx. De todos sus ensayos sobre la lírica nacional, éste es el único que enfoca un período tan extenso. Su punto de partida ahora es la teoría expuesta años antes, en 1934, por Jorge Cuesta en su ensayo "El clasicismo mexicano". Cuesta sostenía que el origen de la poesía española escrita en Nueva España está en las formas renacentistas, universales e italianizantes. Nace no como un casticismo sino como una heterodoxia frente a España. Si la poesía novohispana es, en su origen, una rama del tronco español, habría que agregar que esa tradición española no es nacional sino universal, ya sea en su vertiente renacentista, manierista o barroca. Cuesta es el único miembro del grupo de Contemporáneos que comprende que no tiene sentido hablar de las características "nacionales" de una poesía clásica que es anterior al nacionalismo romántico. A partir de Cuesta, Paz opina que "la heterodoxia frente a la tradición castiza española es nuestra única tradición" (p. 35). El prologuista sintetiza su visión así:

Si algo distingue a la poesía novohispana de la española, es la ausencia o la escasez de elementos medievales. Las raíces de nuestra poesía son universales, como sus ideales. Nacida en la

10 Obras, 2a ed. aum., F.C.E., México, 1966, p. 772. Como todos los textos incluidos en la edición de las Obras carecen de fechas y datos de primera publicación, es difícil establecer las más mínimas nociones cronológicas. En el caso de este texto, se publicó tardíamente en la revista Universidad Michoacana, abril-junio de 1951, núm. 27, pp. 45-52, pero los editores de la revista indican lo siguiente: "El texto corresponde a la versión taquigráfica de una conferencia que el poeta Xavier Villaurrutia dictó con ese título el año de 1942 en el Colegio de San Nicolás". 
madurez del idioma, sus fuentes son las mismas del Renacimiento español. Hija de Garcilaso, Herrera y Góngora, no ha conocido los balbuceos heroicos, la inocencia popular, el realismo y el mito. A diferencia de todas las literaturas modernas, no ha ido de lo regional a lo nacional y de éste a lo universal, sino a la inversa. La infancia de nuestra poesía coincide con el mediodía de la española, a la que pertenece por el idioma y de la que durante siglos no difiere sino por la constante inclinación que la lleva a preferir lo universal a lo castizo, lo intelectual a lo racial (p. 36).

La caracterización es, desde luego, cuestionable: ¿cómo negar la presencia de la epopeya heroica en ciertas zonas de la poesía novohispana? De la época colonial Paz destaca las figuras de Bernardo de Balbuena, Juan Ruiz de Alarcón, Luis de Sandoval Zapata y, en primer lugar, Sor Juana Inés de la Cruz. En estas páginas y bajo la influencia de Cuesta, Paz expresa su convicción (desarrollada años después en su gran libro sobre Sor Juana) de que la presencia de la naturaleza americana en estos poetas no es un antecedente directo de la singularización nacionalista o americanista que llevarán a cabo algunos románticos sino una consecuencia del sincretismo inclusivo de la estética barroca: "La originalidad de Balbuena hay que buscarla en la historia de los estilos y no en la naturaleza sin historia" (p. 37).

Todo el siglo XVIII es despachado como "una época de prosa" (p. 41) mientras los protagonistas del siglo xix son admirados como hombres de acción y patriotas pero condenados como poetas: "Ninguno de ellos -con la excepción, quizá, de Flores, que sí tuvo visión poética aunque careció de originalidad expresiva - tiene conciencia de lo que significaba realmente el romanticismo" (id.). En lugar de enfrentar los temas interiores y dramáticos del "verdadero" romanticismo, los poetas mexicanos "se entregan a una literatura elocuente y sentimental, falsa en su sinceridad epidérmica y pobre en su mismo énfasis" $(i d$.$) . Esta crítica demoledora presupone que el autén-$ tico romanticismo es el que dio sus frutos en Alemania e Inglaterra a fines del siglo XVIII y en las primeras décadas del xIx, y después en Francia: se trata del movimiento que hizo de la poesía una nueva religión, como Paz ha señalado en Los hijos del limo. Si éstos son los términos de la comparación, los epígonos nacionales tienen que aparecer limitados. Por eso, Paz dice que los poetas mexicanos de la época "apenas si rozan la zona de lo sagrado, propia a todo genuino arte romántico" (p. 42). 
Hacia el final del prólogo encontramos unas de las pocas páginas que Paz consagró al modernismo mexicano. Son juicios duros que al final de su vida sentía ganas de rectificar ${ }^{11}$. Aunque rescata los sonetos del Idilio salvaje, ve a su autor, Manuel José Othón, como un "heredero de la corriente académica” (p. 42). A la inversa de Othón, a Salvador Díaz Mirón lo ve como "un romántico que aspira al clasicismo" (p. 43) y le da un tratamiento más justo, tanto por los logros de su libro Lascas como por la perfección parnasiana de su lenguaje: "Frente al lenguaje desvaído de los poetas anteriores -y también frente a las joyas falsas de casi todos los modernistas- la poesía de Díaz Mirón posee la dureza y el esplendor del diamante" (id.). Este "precursor y maestro del modernismo" lleva a cabo una "aventura verbal" y se revela como un heredero mexicano de Baudelaire: es el "primer poeta mexicano que tiene conciencia del mal y de sus atroces posibilidades creadoras" $(i d$.$) .$

Las páginas tan espléndidas que Paz dedicó en 1964 a Darío y al modernismo en "El caracol y la sirena", ensayo recopilado en Cuadrivio, muestran su gran comprensión del movimiento renovador, pero en el texto que comento su visión del modernismo mexicano es sumamente crítica. Acusa a los poetas nacionales de no haberse dado cuenta de la auténtica significación de la tendencia. Mientras que en Hispanoamérica hay una apertura a la tradición universal, en México predomina un enclaustramiento. El modernismo de Manuel Gutiérrez Nájera y de Amado Nervo es visto como un "exotismo" que se contenta con los aspectos más superficiales. En este juicio, Paz sigue de nuevo a Cuesta y a otros Contemporáneos como Villaurrutia ${ }^{12}$. A su vez, Francisco A. de Icaza y Luis G. Urbina son considerados, a pesar de algunos momentos felices, poetas menores. A Enrique González Martínez lo ve como la figura que da gravedad y peso a la sensibilidad modernista. Para Paz (como antes para Cuesta), el autor de Parábolas y otros poemas no rompe con

11 En el prólogo al citado t. 4 de las Obras completas, fechado el 15 de abril de 1991, se lee: "Hoy no podría, por ejemplo, repetir algunas frases desdeñosas acerca de Gutiérrez Nájera y Amado Nervo, que son, con Díaz Mirón y Othón, los fundadores de la poesía mexicana moderna” (p. 24).

${ }^{12}$ No cabe duda de que Cuesta y Villaurrutia son los dos críticos nacionales que más influyen en los tempranos juicios de Paz. En este sentido tuvo razón Luis LEAL al afirmar: "Cuesta, y sobre todo Villaurrutia, son los críticos que preceden a Paz. De ellos desciende directamente" ("Octavio Paz y la literatura nacional: afinidades y oposiciones”, RevIb, 37, 1971, p. 242). 
el modernismo sino que "lo desnuda y despoja. Al despojarlo de sus adherencias sentimentales y parnasianas, lo redime, le otorga conciencia de sí mismo y de su oculta significación" (p. 45). A diferencia de otros que ven en este poeta al primer posmodernista que niega al modernismo, Paz lo ve como "el único poeta realmente modernista que tuvo México" $(i d$.$) . Rea-$ firma así la apreciación que de este poeta hizo Jorge Cuesta: "El conocido verso "Tuércele el cuello al cisne de engañoso plumaje» es una herejía dentro del simbolismo. Sin embargo, González Martínez es el simbolismo mexicano, no a pesar de, sino gracias a esa herejía"13.

Tal como ocurre con su juicio sumamente crítico de los poetas románticos de México, lo que determina esta perspectiva negativa es la necesidad que siente de comparar a los modernistas mexicanos con sus contemporáneos de otras latitudes. Se niega a ver la lírica nacional como un mundo cerrado o aislado e insiste en apreciarla como parte integral de dos sistemas más amplios: el de la poesía hispánica y el de la poesía occidental. En este sentido, el pensamiento crítico (y creador) de Paz es analógico y relacional. Las páginas finales del prólogo hablan de tres figuras modernas, pero como el autor ha consagrado ensayos independientes a Reyes, Tablada y López Velarde, prefiero referirme más adelante a sus textos autónomos sobre estos poetas.

Entre los poetas plenamente modernos estudiados por Paz en ensayos unitarios, voy a centrar mi atención en sus textos sobre Tablada, López Velarde, Reyes, Pellicer, Villaurrutia y Gorostiza. No cabe duda de que éstos son los poetas mexicanos modernos que más fascinación ejercen sobre el autor de Piedra de sol. Como es natural, dedicaré más espacio a las figuras que son más importantes para el comentarista.

Paz ha recopilado dos de los ensayos que escribió sobre José Juan Tablada14. El primero, que comentaré aquí, "Estela de José Juan Tablada", fue redactado y leído apenas un mes después de la muerte de Tablada, acaecida en agosto de 1945 en la ciu-

13 "El clasicismo mexicano", en Obras, ed. Miguel Capistrán et al., Ediciones del Equilibrista, México, 1994, t. 1, p. 313.

${ }^{14}$ En realidad, PAz escribió tres textos sobre Tablada, dos de los cuales están recopilados en el ya citado t. 4: "Estela de José Juan Tablada" (1945) y "Alcance: Poesías de José Juan Tablada" (1972). La nota no recogida es "José Juan Tablada y la música moderna", "La Cultura en México", supl. de Siempre!, 19 de febrero de 1954, núm. 105, p. 20. 
dad de Nueva York, lugar donde Paz trabajaba en el servicio consular. Para apreciar la importancia del texto hay que pensar en la recepción previa de la obra de Tablada. Entre sus compañeros modernistas y entre los miembros del Ateneo de la Juventud, Tablada nunca gozó de un reconocimiento como figura mayor. Aunque casi todos los Contemporáneos recogieron algo de su influencia, prácticamente ninguno lo confesó por escrito. Una excepción parcial es Xavier Villaurrutia quien, en una conferencia leída en 1924 y en la cual se nombra por primera vez al "grupo sin grupo" de los Contemporáneos, habla de las dos fuentes de rebelión para los entonces jóvenes poetas:

Si Enrique González Martínez era, hacia 1918, el dios mayor y casi único de nuestra poesía... necesitamos nuevamente de Adán y de Eva que vinieran a darnos con su rebelión, con su pecado, una tierra nuestra de más amplios panoramas... La fórmula será: Adán y Eva = Ramón López Velarde y José Juan Tablada ${ }^{15}$.

En este irónico esquema seudoteológico de Villaurrutia, Tablada es "el inquieto y el inquietador -Eva de cien manzanas prohibidas-", el liberador técnico del verso. Con cierta injusticia, Villaurrutia limita la influencia de Tablada al aspecto técnico y formal. Para Paz, Tablada deja de ser una curiosidad exótica y se convierte en una figura actual cuyos versos no han perdido nada de su poder de sorpresa. De ahí que la valoración que hace sea mucho más positiva que la de Villaurrutia. Frente al lento ensimismamiento de López Velarde, Tablada es el viajero en busca de novedades, el explorador en cuya obra hay riesgo, aventura, ironía, juego y humor. Su obra es "una pequeña caja de sorpresas" (p. 156), de donde surgen objetos e imágenes de distintas épocas y distintas latitudes. Este apego a la novedad es, al mismo tiempo, una ventaja y una limitación: "Siempre dispuesto a tomar el tren, Tablada es el poeta pasajero, el poeta de lo pasajero" (p. 158).

La parte reducida de la obra de Tablada que le interesa a Paz no son los abundantes versos modernistas sino los libros que aquél publica en Caracas y en Nueva York entre 1919 y 1922: los haikú o "poemas sintéticos" de Un día (1919) y las "disociaciones líricas" en El jarro de flores (1922); y, por otro lado,

15 “La poesía de los jóvenes de México”, en Obras, p. 825. 
las composiciones ideográficas de Li-Po y otros poemas (1920). También se interesa en los poemas de La feria (1928), recreaciones que redescubren al México nacionalista y popular, una vertiente que asomará en su propia poesía en la fase final, sobre todo en el extenso poema "1930: vistas fijas" del libro Árbol adentro (1987). En el caso de los poemas ideográficos, son los mismos que López Velarde no pudo tomar muy en serio, a pesar de su admiración por Tablada y a pesar de que había recibido de éste en 1914 su primer espaldarazo importante en la capital $^{16}$. Casi contemporáneos de los caligramas de Apollinaire, los de Tablada introducen nuevas posibilidades espaciales y pictóricas a un arte simbolista o modernista que nunca se había separado de su matriz musical.

Paz intuye que el haikú de Tablada ha abierto el camino a la vanguardia. Al hacer de la imagen no un elemento más del poema sino el poema en sí, se enfatizaba el poder de concentración y reticencia del texto poético. Como Pound, en lengua inglesa, Tablada entendió que la breve forma oriental ofrecía un modelo de concisión concreta para la poesía nueva de Occidente. Frente a la ampulosidad retórica de gran parte de la poesía modernista, Tablada opone la reducción a un núcleo esencial: la imagen. Además de estas dos formas experimentales que son el haikú y el caligrama, Paz comparte con Tablada una fascinación por el Oriente, una curiosidad universal insaciable, y un vivo interés por las artes plásticas y por el mundo precolombino de México. Poetas viajeros los dos, tienen en común la noción de que la obra de un poeta no tiene por qué ser una lenta acumulación progresiva (como en el caso prototípico de Enrique González Martínez) sino que puede ser también una serie discontinua de cambios y rupturas. Los dos son poetas experimentales de fases o épocas distintas.

El haikú, tal como lo practicó Tablada, se deja sentir en varios momentos de la obra de Paz, sobre todo en las composiciones instantáneas de Piedras sueltas (1955). Pero hay otro poema de Tablada que Paz comenta en su ensayo de 1945, un poema compuesto a dos voces, cada una separada tipográficamente. Se trata de "Nocturno alterno", texto en el cual se

${ }^{16}$ La sensación incómoda de López VELARDE ante esta poesía experimental está expresada en su carta a Tablada fechada el 18 de junio de 1919, reproducida en Obras, ed. José Luis Martínez, 2a ed. aum., F.C.E., México, 1990, pp. 857-858. 
yuxtaponen dos mundos geográficos y dos estados de ánimo (Nueva York y Bogotá), dos mundos que se funden en el final sorpresivo:

Neoyorquina noche dorada

Fríos muros de cal moruna

Rector's champaña fox-trot

Y volviendo la mirada

Casas mudas y fuertes rejas

El alma petrificada

Sobre las silenciosas tejas

Como la mujer de Loth

Los gatos blancos de la luna

Y sin embargo

es una

misma

en New York

y en Bogotá

LA LUNA...!17

Se trata de un texto simultaneísta, forma típica de la vanguardia cubista. Paz no tardará en asimilar la lección ya que en 1948 escribe "Himno entre ruinas", poema muy antologado que tiene la misma forma de bloques textuales espacializados y dispuestos en oposición simétrica. La de Paz es una composición más compleja y ambiciosa ya que incorpora una reflexión sobre la historia contemporánea, pero el antecedente de su hallazgo formal en español está en el poema de Tablada. Además, "Himno entre ruinas" le permite yuxtaponer y contrastar diferentes voces poéticas como parte de una autoexploración. Por otro lado, aunque el modelo formal más importante para un texto espacial y abierto como Blanco (1967) es indudablemente Un coup de dés (1897) de Mallarmé, otros poemas espaciales de Paz de esta época, como los Topoemas (1968), tienen estrechos paralelismos con las composiciones ideográficas de Tablada. En 1966, en la antología Poesía en movimiento, Tablada aparece como el primer poeta de la ruptura en México. Por primera vez en una antología, Tablada es visto como el padre de la poesía

17 José Juan Tablada, "Nocturno alterno”, en Obras, t. 1: Poesía, ed. Héctor Valdés, UNAM, México, 1971, p. 407. 
moderna. Al lado de López Velarde y Pellicer, Tablada sería, desde la perspectiva de Paz, el fundador de una modernidad abierta y dinámica: es el primer poeta vanguardista de México. Sería difícil exagerar la importancia de esta lectura pionera de 1945 para la reconfiguración del canon poético mexicano: junto con los trabajos de José María González de Mendoza (el "Abate"), el ensayo de Paz inició la revaloración de este poeta tan innovador, dándole un lugar central en la tradición moderna ${ }^{18}$.

Paz escribió dos textos sobre López Velarde: un ensayo de 1950, "El lenguaje de López Velarde", recogido en Las peras del olmo (1957), y otro mucho más extenso que ha sufrido ampliaciones. Este último, "El camino de la pasión: Ramón López Velarde", escrito en 1963 (estimulado por la lectura del libro de Allen W. Phillips, Ramón López Velarde, el poeta y el prosista) se recogió en Cuadrivio (1965), pero cito aquí de la versión más extensa que se incluye en el ya mencionado tomo de las Obras completas porque desarrolla largamente puntos del ensayo anterior e incorpora párrafos nuevos añadidos en 1986 además de un post-scriptum fechado en 1987. Poco conocido fuera de México, López Velarde goza de un extraño prestigio: "poeta de la provincia" para algunos; "poeta nacional" para otros (es el autor de "La suave patria", uno de nuestros pocos himnos cívicos que se puede leer como poesía), es una figura que ha sido clasificada con demasiada facilidad. No cabe duda de que entre los distintos modelos poéticos nacionales que asumen los jóvenes Contemporáneos (González Martínez, Tablada y López Velarde), este último es el más hondo y más complejo. Si la cantidad e intensidad de las páginas críticas consagradas a una figura indica una fascinación permanente y obsesiva, entonces se puede afirmar que después de la figura de Sor Juana Inés de la Cruz, López Velarde es el poeta mexicano que más atrae a Paz. Esta fascinación se da desde muy temprano: en una conferencia leída en plena guerra civil, en Valencia en 1937, Paz declara que López Velarde representa "el nacimiento de una nueva poesía" y no duda en reconocer en este poeta "un origen, nuestro origen"19.

18 Para una antología de muchos de los ensayos dispersos del "AвAтE" Mendoza sobre Tablada, véase Ensayos selectos, Tezontle, México, 1970, pp. 114-198.

19 "Noticia de la poesía mexicana contemporánea (Palabras en la Casa de la Cultura de Valencia)", Miscelánea I. Primeros escritos, t. 13 de las Obras completas de Octavio Paz, 2a ed., F.C.E., México, 1999, p. 261. 
Se rechaza desde el principio la clasificación reduccionista del autor como "poeta de la provincia" o "poeta nacional". Paz se atreve a leerlo dentro de un contexto universal y éste es tal vez su logro mayor, sólo anticipado por un ensayo de Xavier Villaurrutia ${ }^{20}$. En las primeras páginas el crítico se dedica a rastrear y comentar diversas influencias menores de poetas mexicanos (Tablada, Nervo, Rebolledo), hispanoamericanos (Darío, Herrera y Reissig), españoles (muy especialmente, en páginas agregadas en 1986, Andrés González Blanco, el poeta melancólico de la provincia) y franceses y belgas (Jammes y Rodenbach), antes de analizar la cuestión de las influencias mayores. Aquí entramos en un terreno menos exterior y más íntimo. Paz estudia los vasos comunicantes que enlazan a López Velarde con Baudelaire, Laforgue y Lugones. Contra lo que había afirmado en su ensayo de 1950 - "el lenguaje de López Velarde no ostenta huella alguna del poeta francés" (p. 166)-, ahora subraya las semejanzas entre el mexicano y Baudelaire, semejanzas que van desde el dualismo psíquico hasta la voluntaria confusión de lo religioso y lo erótico. Gracias a su perspectiva universal y comparatista, Paz logra percibir elementos que de otra manera no saldrían a la luz: me refiero a la fascinación erótica baudelaireana ante la carne y la muerte, fascinación con olor a sacrilegio; a la lección del prosaísmo, la práctica del monólogo y el recurso del desdoblamiento irónico y sentimental aprendidos de Laforgue; y a cierto tipo de lenguaje, adjetivación insólita y giros lingüísticos practicados antes por Lugones.

El logro más alto de López Velarde, para Paz, es la creación de un lenguaje propio, nuevo, que incorpora ritmos y tonos de la lengua coloquial. ¿Cómo inventó este lenguaje tan personal $\mathrm{y}$ tan intransferible? A diferencia de los poetas españoles, como Antonio Machado, que cultivaban una lengua estética popular, folclórica y arcaizante, López Velarde comprende que el lenguaje de la poesía sólo puede partir de la lengua coloquial de la conversación cotidiana. Para Paz, el lenguaje neopopular de Machado y varios de los jóvenes poetas de la Generación del 27 revela nostalgia tradicionalista mientras que el prosaísmo de López Velarde abre las puertas a la conciencia de lo nuevo, a la crítica de la modernidad, al choque de lo heteróclito. La forma libre y flexible que tiene el monólogo en López Velarde es el instrumento idóneo para una poesía que explora los vericuetos

20 Véase “Ramón López Velarde”, en Villaurrutia, Obras, pp. 641-659. 
de la conciencia. Para Paz, el zacatecano es el poeta de la conciencia solitaria, de la introspección y el análisis. Aunque hay muchas ausencias en su obra (Paz lamenta la ausencia de la historia y del "conocimiento y sus dramas", de la rebeldía y los sueños utópicos del pensamiento moderno), su originalidad reside en este acto prodigioso de invención de un lenguaje expresivo, "creación inimitable, fusión rara de la conversación y de la imagen insólita" (p. 185). Por eso su criollismo o nacionalismo es "una actitud estética" y no la ejemplificación de un programa político o cultural. Y por lo mismo, Paz salva al poema público o cívico "La suave patria". Aunque no deja de enumerar lo que le parecen ser sus defectos y caídas (lo que llama "ciertos lunares y flaquezas"), Paz defiende la ética y la estética personales del poema: "«La suave patria» tolera las complicidades sentimentales, no las ideológicas" (p. 190).

En la segunda parte del ensayo Paz explora los temas obsesivos de la poesía de López Velarde (temas que son, también, los suyos): amor, erotismo, placer, temporalidad y muerte. El alto lugar que Paz da a la poesía de López Velarde se debe, creo, a la intensidad y profundidad de un puñado de poemas de Zozobra (1919), libro central para el comentarista. Más que un poeta del amor, es un poeta erótico, enamorado de la fuerza amorosa y no tanto de la persona amada. Como Paz después, López Velarde "decide habitar el instante", con todos los riesgos que esto implica. Hay un perspicaz análisis de las distintas manifestaciones de la figura femenina en esta poesía, desde la inaccesible Fuensanta de la provincia católica hasta las mujeres dispensadoras de placer encontradas en la gran ciudad. Lo que da intensidad y dramatismo a estos poemas eróticos es la conciencia temporal: "En la libertad erótica de la mujer reconoce la suya y sobre esas dos libertades funda una hermandad. Es una fraternidad vertiginosa porque se apoya en el instante: fundación en un abismo" (p. 197). Precisamente por ser un poeta erótico con la conciencia lúcida, López Velarde se siente atraído por la destrucción y la muerte: "El abrazo, la metáfora pasional, es un arrojarse juntos al despeñadero" (p. 199). Es en esta parte del ensayo donde se siente la mayor comunión entre los dos poetas. La razón es obvia: López Velarde y Paz son, tal vez, los dos más grandes poetas eróticos de la tradición mexicana. El poeta y crítico se identifica tanto con este aspecto de su precursor, que proyecta sobre éste su filosofía del amor y del erotismo. Así, cuando enuncia una conclusión acerca de López 
Velarde, nos convence porque la sentencia resume también su experiencia como poeta y ensayista: "Placer y muerte son las dos caras de una misma medalla" (p. 200). Por lo tanto, hay que tener muy presente su declaración inicial en la cual habla de sus motivos para volver a escribir sobre este poeta: "Yo me propuse, una vez más, interrogar a esos poemas -como quien se interroga a sí mismo. Las páginas que siguen son mi respuesta" (pp. 172-173). La crítica se vuelve, en muchos momentos, autocrítica.

La tercera parte del ensayo, que trata de las creencias de López Velarde, es un intento por leer al poeta dentro de la tradición central de Occidente y especialmente dentro de la tradición amorosa que tiene su semilla en el amor cortés. Paz se basa en el conocido libro de Denis de Rougemont, Amor y Occidente, que propone que la doctrina del amor-pasión de los trovadores provenzales surge como manifestación de la herejía cristiana de los cátaros. Esta herejía consistía en el maniqueísmo, es decir la insalvable y definitiva dualidad entre materia y espíritu, entre cuerpo y alma. La interpretación de Paz es arriesgada porque lee en el dualismo radical de López Velarde no un simple rasgo biográfico o psíquico sino una creencia profunda derivada, en última instancia, de las antiguas filosofías heréticas. El rechazo que el poeta siempre tuvo a la procreación (porque reproduce el mal) sería, así, una reiteración de la herejía maniqueísta. ¿Tuvo el poeta conciencia de esto? No lo sabemos. Paz sostiene más bien que al beber en las fuentes tradicionales de la poesía amorosa de Occidente, López Velarde asimiló estas doctrinas y que la identificación del amor/ erotismo con la religión y la muerte debe verse no como accidente de su biografía sino como consecuencia natural de sus lecturas y formación cultural. Se lanza así un reto para la crítica posterior y se abre la posibilidad de nuevas interpretaciones no contempladas por los estrechos estereotipos que se habían aplicado a este poeta.

Las huellas de López Velarde están presentes, como podría esperarse, en muchos de los poemas eróticos de Paz. Pero hay otros aspectos de su obra que han influido en Paz, incluso aspectos formales que no puedo analizar en detalle aquí, como sería la apropiación personal que Paz hace de la silva moderna, forma métrica que López Velarde perfeccionó en múltiples poemas. Además, ¿cómo no reconocer que "El retorno maléfico" es uno de los subtextos estructurantes del poema "Vuelta" 
de Paz? Los dos relatan el retorno a la casa familiar y el encuentro con cierta desolación en un espacio degradado. El epígrafe de "Vuelta" consta de los primeros versos escalofriantes del poema de López Velarde:

Mejor será no regresar al pueblo, al edén subvertido que se calla en la mutilación de la metralla21.

La relación que existió entre Paz y Alfonso Reyes es sumamente importante, como lo demuestra el extenso epistolario entre los dos que se publicó hace poco ${ }^{22}$. Sin embargo, los dos mayores ensayistas del siglo xx en México tuvieron gustos y prácticas distintos en la poesía. El clasicismo de Reyes se opone al marcado romanticismo de Paz y sus respectivas visiones de la "experiencia literaria" no pueden ser más opuestas, como he argumentado en otro lugar al comparar y contrastar El deslinde con El arco y la lira ${ }^{23}$. Reyes es otro poeta de difícil clasificación. Como López Velarde, se encuentra entre el modernismo y el vanguardismo, en ese espacio anfibio que algunos llaman el posmodernismo poético. Es significativo, en este sentido, que en el ensayo que escribió a raíz de la muerte de Reyes, "El jinete del aire: Alfonso Reyes", redactado en los primeros días de 1960, Paz no haya sido tan abundante en sus comentarios sobre la poesía del regiomontano. Con excepción de Ifigenia cruel, calificada como "su obra poética más perfecta" (p. 228) y celebrada por su belleza y complejidad, la obra en verso de Reyes recibe poca atención. Este texto crítico describe y recrea más bien el espíritu de Reyes: hombre cordial, enamorado de la forma, la mesura y el equilibrio.

Sin embargo, el que creía en la armonía esencial de todo lo existente tenía que parecer algo anacrónico a un joven atraído por las vanguardias y la gran aventura de la poesía moderna con su carga de desmesura. Además, Reyes practica en su lírica un retorno a la poesía popular y tradicional (coplas, canciones y romances, por ejemplo) que Paz no veía como el camino de

21 "El retorno maléfico", en Obras, p. 206.

22 Alfonso Reyes/Octavio Paz: correspondencia (1939-1959), ed. Anthony Stanton, Fundación Octavio Paz-F.C.E., México, 1998.

23 Véase mi ensayo "Alfonso Reyes, Octavio Paz y el análisis del fenómeno poético”, en el ya citado Inventores de tradición, pp. 205-220. 
la poesía moderna. En este sentido, es indudable que el lenguaje poético de López Velarde le interesa mucho más que el de Reyes. Me parece que aunque Paz reinvindica zonas de la poesía de Reyes, éste le importa más como ensayista y hombre de letras. Los separaban demasiadas cosas como poetas: el tradicionalismo de Reyes contrasta con el experimentalismo de Paz. Dos caminos distintos y, sin embargo, hay momentos de intersección como cuando Paz retoma y reescribe en "Nocturno de San Ildefonso" el poema de Reyes llamado precisamente "San Ildefonso". En ambos poemas hay el mismo desdoblamiento del yo que explora su pasado e infancia desde el presente de la madurez. Escribe Reyes:

Tal vez no fui dichoso.

Yo era otro, siendo el mismo:

yo era el que quiere irse ${ }^{24}$.

Y escribe Paz como si fuera una respuesta:

El muchacho que camina por este poema, entre San Ildefonso y el Zócalo, es el hombre que lo escribe: esta página también es una caminata nocturna ${ }^{25}$.

Carlos Pellicer tiene un lugar muy especial en la formación poética de Paz. Fue su maestro de literatura en la Escuela Nacional Preparatoria y es el poeta que más influye en los inicios del joven. En "Juego", primer poema publicado por Paz a los 17 años, no es difícil reconocer la voz de su maestro. "Juego" es una declaración y realización de arte poética, un homenaje a la vanguardia lúdica:

Saquearé a las estaciones.

Jugaré con los meses y los años.

(Días de invierno con caras rojas de veranos.) ${ }^{26}$

24 "San Ildefonso", Constancia poética, t. 10 de las Obras completas de ALFONSO Reyes, F.C.E., México, 1959, p. 218.

25 "Nocturno de San Ildefonso", Vuelta, Seix Barral, Barcelona, 1976, p. 77.

${ }_{26}$ Para el texto completo del poema y un comentario, véase ANTHONY Stanton, "El primer poema de Octavio Paz", La Jornada Semanal, nueva época, 14 de diciembre de 1997, núm. 145, 10-11. 
El conocido modelo pelliceriano se llama "Estudio" y aparece en su primer libro de 1921. Comienza así:

Jugaré con las casas de Curazao, pondré el mar a la izquierda y haré más puentes movedizos. ¡Lo que diga el poeta! ${ }^{27}$

Los mismos verbos "performativos" en futuro, la misma concepción plástica, el mismo poderío cosmogónico del artista. No sería exagerado afirmar que Pellicer representa para el joven en aquel momento algo así como la encarnación de la poesía moderna. En los dos poemas citados se nota la celebración del espíritu juvenil, deportivo y lúdico de cierta vanguardia despreocupada. El poeta ordena e inventa el mundo mientras lo real se metamorfosea gracias al poder transformador de la imagen.

En "La poesía de Carlos Pellicer", ensayo de 1955, Paz lo define como "nuestro primer poeta realmente moderno" (p. 234). Poeta de la imagen que vuela, de la luz, el sol y el mar, poeta de "una prodigiosa sucesión de metáforas e impresiones visuales y sonoras" (id.), Pellicer deslumbra por la velocidad y dinamismo de sus imágenes. Lo que sorprende en este ensayo es el contagio que ejerce el estilo metafórico de Pellicer sobre la prosa crítica de Paz: el texto se vuelve a veces un encadenamiento de imágenes ${ }^{28}$. Hay una frase de doble filo que Paz enuncia y que es un elogio y una crítica: "Pellicer no es un poeta de poemas sino de instantes poéticos" (p. 237). Cualquier lector familiarizado con la poesía de Paz sabe de la importancia central del "instante poético" como lugar de encuentro y fusión, pero la reserva consiste en el hecho de que para Paz, Pellicer no es capaz de construir o estructurar un poema de más largo aliento: es decir, sus obras de cierta extensión tienden a ser una sucesión de metáforas en lugar de una arquitectura. El

27 En Obras. Poesía, ed. Luis Mario Schneider, F.C.E., México, 1981, p. 23. Es curioso que PAz haya citado dos de estos mismos versos en su primer ensayo autónomo sobre el poeta: "Carlos Pellicer y la poesía de la naturaleza" (1941), recogido en el ya citado t. 13 de las Obras completas, p. 297.

${ }^{28}$ Esta presencia de la prosa poética y la abundancia de metáforas que saturan la prosa crítica de este ensayo fueron notadas en un acercamiento reciente a los textos críticos incluidos en la primera parte de Las peras del olmo: veáse J. Agustín Pastén B., Octavio Paz: crítico practicante en busca de una poética, Pliegos, Madrid, 1999, p. 92. 
mejor Pellicer, para Paz, es el autor de las composiciones breves con sus sorprendentes metáforas.

La estrategia de lectura más notable en este ensayo es la comparación contrastiva que Paz establece entre Pellicer y Villaurrutia. Si el primero es el poeta para quien el mundo exterior existe, el segundo es el de la conciencia reflexiva. Villaurrutia representa un polo de atracción opuesto al primero y que ya no articula la expansión jubilosa o la participación lúdica en lo real sino el destierro del yo en la vigilia reflexiva de un solipsismo que horada las profundidades psíquicas del ser. Así, frente al movimiento centrífugo de Pellicer tenemos un movimiento de signo contrario: hacia adentro. Frente a la poesía de las sensaciones, la de la reflexión; frente al viaje de descubrimiento del mundo, el viaje interior de la introspección; frente a la riqueza sensorial, el abismo de la inteligencia.

Todo esto puede verse también en uno de los primeros poemas de Paz, escrito apenas unos meses después del inaugural "Juego". Se trata de "Nocturno de la ciudad abandonada", que se publicó en el número 4 de la revista Barandal en noviembre de 1931. Es el primer poema "urbano" del autor. La penúltima estrofa dice así:

\section{(Los viajes azules de los pájaros jamás escucharon silencio y sombra muerta tan igual.)}

Alusión a una voz desplazada: "los viajes azules de los pájaros" han sido ensombrecidos o, más bien, se afirma que son incapaces de percibir los aspectos más oscuros de la existencia. La otra voz no ha sido cancelada sino relativizada. Así, la nueva voz se justifica al señalar la insuficiencia de la voz anterior. El recurso formal de encerrar esta estrofa entre paréntesis recalca la idea de que es una voz desplazada. Se tiene conciencia de la existencia de dos voces: la pelliceriana y esta otra, desolada y reflexiva. No es un simple cambio de registro sino algo más complejo: una conciencia metapoética, dueño de dos voces distintas, sabe que estas voces son a la vez incompatibles y mutuamente necesarias. La identidad del poeta está fracturada en dos sensibilidades que siente como "suyas", aunque las dos sean "prestadas". Hay un intento aquí de acercarse al mundo de los nocturnos de Xavier Villaurrutia, quien es, junto con Pellicer, el otro poeta de los Contemporáneos que atrae al joven en este momento. 
Si señalo un parecido con Villaurrutia, se debe no sólo al título y al ambiente sino a ciertas imágenes de la segunda parte que registran sensaciones por medio de una sinestesia negativa: "Se oye, metálica, a la sombra caer/ en el piso - tan sólido y compacto-". ¿No hay aquí algo que se asemeja al procedimiento villaurrutiano de mezclar percepciones sensoriales desrealizadas para vaciar la realidad de su consistencia material, interiorizarla y borrar los límites de lo finito, creando un mundo angustioso de huecos, ausencias, ecos y sombras? Este diálogo con Villaurrutia continúa en otros poemas posteriores de Paz, como "El desconocido" y los sonetos de "Crepúsculos de la ciudad". Por otro lado, tanto Villaurrutia como Paz reaccionan en forma parecida ante el surrealismo oponiendo a las fuerzas irracionales el dique de la conciencia. De ahí que no sea exagerado aplicar al autor de la frase la conclusión de Paz acerca de la poética de Villaurrutia: "Su poesía parte de la conciencia de la dualidad y es una tentativa por resolverla en unidad. Pero unidad que no destruye la dualidad sino que, al contrario, la preserva y en ella se preserva" (p. 276).

En el ensayo de 1955 sobre Pellicer se racionaliza algo que el poeta había expresado intuitivamente años antes. Este "hallazgo" puede resumirse diciendo que al autolimitarse, las voces de Pellicer y de Villaurrutia se encierran y se mutilan: "Ambos poetas, al mismo tiempo dueños y esclavos de sus dones, son un ejemplo de la libre fatalidad poética. Cada uno es rey de su mundo poético. Rey y prisionero, pues está condenado a no traspasar sus límites" (p. 238). La obra poética y ensayística de Paz será, creo, un intento ambicioso de traspasar estos límites y configurar un mundo poético más amplio y abarcador.

En los textos escritos sobre otros miembros del grupo de Contemporáneos, específicamente los que tratan de Xavier Villaurrutia y José Gorostiza, creo que se puede notar la misma ambivalencia de elogio y reserva. En la peculiar terminología que Paz había desarrollado en un ensayo de juventud, los Contemporáneos serían poetas no de comunión sino de soledad, juicio discutible pero revelador: "En los poemas de Gorostiza, Villaurrutia y Ortiz de Montellano no hay nadie; todos y todo se han vuelto reflejos, espectros" (p. 76). En un claro intento de diferenciar a su generación y, sobre todo, a sí mismo de los Contemporáneos, Paz ha escrito que sus antecesores no sintieron "la doble fascinación de la política y la religión (o de la «otra religión»: la tradición hermética)" (p. 82). Ciertamente, 
los Contemporáneos, en términos generales, no simpatizaron con el afán subversivo, rebelde y utópico que se manifiesta en el surrealismo y otros movimientos de vanguardia, aunque tal vez habría que exceptuar a Jorge Cuesta de esta generalización, no porque haya aceptado la estética surrealista (de hecho, Cuesta siempre se opuso al irracionalismo en nombre del rigor y la inteligencia) sino por la gran comprensión que mostró de los problemas centrales del pensamiento surrealista. Otra excepción parcial sería Ortiz de Montellano, un poeta obsesionado por el mundo onírico y que intenta expresar, en su poema extenso Primero sueño (1931), la lógica asociativa y arbitraria de los sueños.

Por lo que se refiere al juicio sobre la nula fascinación por la tradición hermética, Paz lo reitera con más fuerza en el mismo texto, Xavier Villaurrutia en persona y en obra, escrito en 1977: "Sería inútil buscar en ellos las huellas de la «otra religión» que, desde el hermetismo neoplatónico del Renacimiento y a través de diversas formas - la cábala, la alquimia, el pensamiento analógico- no ha cesado de fascinar a la conciencia poética de Occidente" (p. 89). Asimismo, en un breve ensayo motivado por la publicación en 1980 del libro de Jaime García Terrés, Poesía y alquimia: los tres mundos de Gilberto Owen, Paz vuelve a poner en tela de juicio las lecturas herméticas o alquimistas (como la que practica en su libro García Terrés en torno a Simbad el varado de Owen), denuncia los peligros que entrañan estas interpretaciones y termina por negar cualquier tipo de relación entre los Contemporáneos y la tradición hermética: "Como su generación, [Owen] fue insensible a la fascinación de la otra religión de Occidente. Ni su vida, ni sus lecturas, ni su correspondencia, ni sus poemas, ni sus prosas nos ofrecen indicios de que alguna vez hubiese frecuentado la tradición esotérica" (p. 281).

Los juicios anteriores son contundentes y tajantes, pero tal vez habría que matizarlos o verlos como lo que creo que son: una afirmación de primacía que hace Octavio Paz, el gran defensor del surrealismo y el gran explorador del hermetismo (en Sor Juana Inés de la Cruz y en Darío, por citar dos ejemplos conocidos de sus lecturas "herméticas"). Lo que estoy señalando no es la inexactitud de estas interpretaciones de poetas anteriores sino algo más importante: la naturaleza estratégica de su lectura. Tiende a no ver, a subestimar o a negar en los demás lo que él quiere hacer en sus escritos. Sus lecturas son interesa- 
das y no deben ser tomadas con ingenuidad. Tomados al pie de la letra, estos juicios son excesivamente tajantes y sería fácil demostrar que las generalizaciones son demasiado absolutas. Además, hay que tomar en cuenta las fechas: Paz escribe estos textos en la última etapa de su vida, en un momento en que él reescribe la historia de la poesía mexicana desde una posición dominante y con la intención de subrayar la originalidad de las contribuciones de su generación. Pocos años después, en 1982 y 1983, escribe dos importantes ensayos de reinterpretación de la tradición poética mexicana e hispánica: "Poesía e historia: Laurel y nosotros", el epílogo para una nueva edición de la famosa antología de 1941, y "Antevíspera: Taller (1938-1941)", una especie de testimonio crítico y balance del lugar y los logros de su generación, la de la revista Taller.

Hay que mostrar el mismo escepticismo ante su aseveración de que "el erotismo no es una nota distintiva de los «Contemporáneos»" (p. 90). Al negarles a sus precursores locales la presencia de una dimensión erótica, se está reservando un espacio como el gran explorador del erotismo que es, efectivamente, Octavio Paz en su poesía y en su prosa. Sin embargo, desde otra posición uno podría argumentar que sí existe una veta erótica en ciertas zonas de la poesía de Villaurrutia, Novo y Pellicer: no un erotismo celebratorio del amor plenamente realizado (como el que existe en la poesía de Paz), sino el erotismo como un impulso igualmente intenso e indudablemente más trágico porque está condenado a ser perpetuo deseo. Es decir, el poeta-intérprete se distancia de la manifestación peculiar del erotismo en los poetas nombrados (y en otros poetas eróticos importantes para Paz, como sería el caso de Luis Cernuda) porque las búsquedas de éstos no coinciden con las suyas en sus resultados.

Una conclusión parecida se puede derivar de la siguiente observación de Paz: "en nuestra formación aparecen corrientes que a ellos [los Contemporáneos] apenas si les tocaron: el marxismo, Freud, la fenomenología y el pensamiento de Heidegger" (p. 84). Cuando hace declaraciones de este tipo es porque quiere distinguir a su generación de la de los Contemporáneos. Es natural, entonces, que tienda a subrayar con excesiva nitidez los contrastes y a negar lo que parecen ser claros antecedentes de su obra.

La última lectura de uno de los Contemporáneos que quisiera comentar aquí es el ensayo sobre Muerte sin fin, el capital poe- 
ma extenso que publicó en 1939 José Gorostiza. Escrito en 1951, este texto interpretativo se ha vuelto clásico también, pero no creo que todos los que lo han aprovechado se hayan dado plena cuenta de las dimensiones de la lectura. Hay varios presupuestos ocultos que convendría explicitar para poder apreciar la importancia de este ensayo crítico. Como en el texto sobre Pellicer, Paz comienza por establecer una oposición entre dos tipos de poeta: los abundantes que se dejan llevar por "la embriaguez verbal" (podríamos pensar en Neruda o en Pellicer) y, por contraste, los poetas breves y concentrados (como Gorostiza). Después de una lúcida descripción del poema y de sus modelos antiguos y modernos, Paz resume las fecundas contradicciones centrales de la composición de la siguiente manera:

Muerte sin fin es el poema de lo temporal, como su nombre mismo lo proclama, pero su lenguaje es resplandeciente, escultórico y abstracto. Es el poema de la palabra al mismo tiempo que de su destrucción. Himno, es también discurso; canto, es demostración; sátira, elegía. Canta la muerte de la forma en versos de tal belleza formal que la glorifican. Es un poema filosófico que implica la muerte de la filosofía. Poesía intelectual -en el más alto de los sentidos-, proclama el triunfo de lo irracional; vitalista, el de la muerte (p. 247).

El poema aparece, en esta visión, como una especie de síntesis hegeliana absoluta de cierto tipo de poesía, de cierto tipo de poética. Cuando concluye que "Muerte sin fin marca el apogeo de cierto estilo de 'poesía pura' y, simultáneamente, es una burla de ese mismo estilo" (id.), creo que Paz está tratando de colocar al poema en un lugar especial: muy alto, ciertamente, pero un lugar de clausura. Por eso se permite hablar de "la grandeza, la originalidad y, asimismo, las limitaciones del poema" (p. 248). Más que un texto que abre un camino a la poesía futura, el poema de Gorostiza es visto como un mausoleo que pone fin a una tradición. Al llevar a su límite crítico y paródico la tendencia estética purista, en la cual la poesía es una constante reflexión sobre su esencia y sobre el acto de poetizar, acto encerrado en el esencialismo restrictivo del mundo poético, Gorostiza hace un homenaje a lo que él había llamado "una poesía de asfixia”.

Si Muerte sin fin es un modelo para un poeta posterior como Paz, habría que reconocer que es un modelo no para ser imita- 
do sino para ser superado desde presupuestos muy distintos. Paz está pensando seguramente en su futura respuesta creadora al poema cuando escribe: "Muerte sin fin cierra un ciclo de poesía: es el monumento que la forma ha erigido a su propia muerte. Después de Muerte sin fin la experiencia del poema -en el sentido de Gorostiza - es imposible e impensable. Otras experiencias, otras muertes, nos esperan" (p. 249). Efectivamente, la experiencia de un poema como Piedra de sol es muy distinta y representa una reescritura positiva de lo que Paz entiende como el nihilismo de Gorostiza. En los términos ya esbozados por aquél, Piedra de sol aspira a ser una poesía de comunión que contiene en su interior, asimilada y sintetizada, la experiencia de la soledad. Para retomar los términos de la lógica hegeliana ya invocados, en un primer movimiento Paz lee el poema de Gorostiza como síntesis o resolución perfecta de todo un desarrollo anterior de la poesía occidental, pero en un segundo movimiento (que es, en realidad, simultáneo) reubica y refuncionaliza esa síntesis ya no como punto final sino como la nueva tesis de otro proceso dialéctico en el cual se tendrá que oponer una antítesis en busca de una nueva síntesis más englobadora. Es decir, su lectura crítica de Muerte sin fin forma parte de un programa estético creador que ve en el poema de Gorostiza no sólo la clausura de una poética determinada sino también la justificación de una poética alternativa.

De las páginas anteriores me parece que se desprenden algunas conclusiones. Espero haber demostrado que la lectura crítica que Paz hace de ciertas figuras de la tradición anterior funciona como una poderosa legitimación de su obra poética. No es, ni se propone ser, un lector objetivo, ecuánime o desinteresado: es un intérprete revisionista (en el sentido que Harold Bloom da a esta palabra) que constantemente busca apoyos en la tradición - tanto armónicos como antagónicos- para sus propuestas creadoras personales. Sus estrategias de lectura trabajan siempre en el sentido de crear síntesis más englobadoras que parecen tener mayor poder explicativo que las lecturas previas. No sólo quiero decir que Paz es mejor lector que sus antecesores porque tiene la capacidad de insertar sus interpretaciones en una tradición más amplia o más universal sino también que es muy difícil no leer con los ojos de Paz la obra de ciertos poetas anteriores.

Una de las características más importantes de su obra poética y ensayística es esta singular capacidad de construirse como 
una prolongación crítica y una síntesis imaginativa original a partir de las obras de aquellos precursores escogidos por él: intenta no sólo asimilar y completar a ciertos poetas anteriores sino también trascenderlos. En este sentido, es indudable que su obra creadora y crítica posee unas dimensiones más ambiciosas que las de sus antecesores inmediatos. Sus estrategias hermenéuticas fueron útiles y fecundas y su éxito las ha erigido en una especie de norma inimitable e irrepetible. Por eso mismo, aunque nos falta todavía perspectiva para apreciar los logros de esta obra en su totalidad puesto que sólo la poesía y la crítica del futuro ofrecerán un punto de vista clave sobre el grado de continuidad de esta lógica de interpretación, me parece inevitable asentar que desde la perspectiva de hoy esta obra se presenta con toda naturalidad como el paradigma central de la poesía mexicana del siglo xx: sintetiza y reformula a sus precursores a la vez que anticipa tendencias posteriores. El día de hoy el canon de la poesía mexicana moderna sigue dominado por las estrategias interpretativas del crítico y poeta Octavio Paz. Nadie como él ha logrado articular y argumentar en forma tan brillante (y nada caprichosa) sus preferencias, antipatías y necesidades. Mediante inclusiones y exclusiones razonadas nos ha dejado una visión jerárquica que concede valor y preeminencia a ciertas obras en detrimento de otras. No cabe duda de que sus lecturas siguen siendo canónicas y creo que así quedarán hasta que surja otra figura capaz de hacer con la obra de Paz lo que éste hizo con la de sus precursores. Sin embargo, como esta posibilidad es remota, tal vez tendríamos que aceptar que en la actualidad son difícilmente repetibles las interpretaciones críticas y creadoras en el esquema totalizador que propone Octavio Paz. Si fuera así, habría que buscar en el futuro otros modelos descriptivos de explicación para esa construcción imaginaria que llamamos el canon.

Anthony Stanton El Colegio de México 